\title{
ARTIGOS
}

\section{CRIACIONISMO: TRANSFORMAÇÕES HISTÓRICAS E IMPLICAÇÕES PARA O ENSINO DE CIÊNCIAS E BIOLOGIA}

LUIIS FERNANDO MARQUES DORVILLÉ • SANDRA LÚCIA ESCOVEDO SELLES

\section{RESUMO}

Ao longo das últimas décadas, um número crescente de comunidades evangélicas e adventistas tem defendido o criacionismo em nosso país. Este artigo se propõe a examinar as matrizes identitárias desse movimento, suas transformações ao longo do tempo e a influência de seus discursos na sociedade, em particular no ensino de ciências e biologia. Sugere-se que o enfrentamento dessa situação deva envolver práticas que contribuam para uma melhor compreensão da atividade científica, enfatizando a relevância da sua abordagem na formação inicial. É destacada ainda a importância de atividades didáticas capazes de promover um ambiente de respeito pelas diferentes visões de mundo ao mesmo tempo em que trabalham o conhecimento transmitido pela ótica do estranhamento, desabilitando zonas de conforto.

ENSINO DE CIÊNCIAS • BIOLOGIA • CRIACIONISMO • RELIGIÃO

CREATIONISM: HISTORIC CHANGES AND IMPLICATIONS FOR THE TEACHING OF SCIENCE AND BIOLOGY

\section{ABSTRACT}

Over the past few decades, a growing number of Protestant and Adventist communities has defended creationism in Brazil. This article aims to examine the identity matrices of this movement, its transformations over time and the influence of its discourse in society; in particular, in science and biology education. It is suggested that, to deal with this situation, practices that contribute to a better understanding of scientific activity and emphasize the importance of its approach in general education should be applied. This article also highlights the relevance of educational activities capable of promoting an environment of respect for other worldviews and of dealing with the knowledge transmitted by the view of estrangement, upsetting comfort zones. 


\section{CRÉATIONNISME: TRANSFORMATIONS HISTORIQUES ET IMPLICATIONS POUR L'ENSEIGNEMENT DES SCIENCES ET DE LA BIOLOGIE}

RÉSUMÉ

Tout au long des dernières décennies, un nombre croissant de communautés évangéliques et adventistes défendent le créationnisme au Brésil. Cet article propose d'examiner les matrices identitaires de ce mouvement, ses transformations dans le temps et l'influence de ses discours dans la société, notamment, dans l'enseignement des sciences et de la biologie. Il y est suggéré que l'affrontement de cette situation doit comprendre des pratiques contribuant à une meilleure compréhension de l'activité sicentifique. L'importance de son approche dans la formation initiale est mise en avant, de même que celle des activités didactiques capables de promouvoir une ambiance de respect envers les différentes visions du monde, tout en explorant la connaissance transmise sous l'optique de la défamiliarisation, de manière à désactiver les zones de confort.

ENSEIGNEMENT DES SCIENCES • BIOLOGIE • CRÉATIONNISME • RELIGION

CREACIONISMO: TRANSFORMACIONES HISTÓRICAS E IMPLICACIONES PARA LA ENSEÑANZA DE CIENCIAS Y BIOLOGÍA

RESUMEN

A lo largo de las últimas décadas, un creciente número de comunidades evangélicas y adventistas ha defendido el creacionismo en Brasil. Este artículo se propone a examinar las matrices de identidad de dicho movimiento, sus transformaciones con el paso del tiempo y la influencia de sus discursos en la sociedad, sobre todo en la enseñanza de ciencias y biología. Se sugiere que el enfrentamiento de tal situación involucre prácticas que contribuyan para comprender mejor la actividad científica, enfatizando la pertinencia de su abordaje en la formación inicial. Se destaca asimismo la importancia de actividades didácticas capaces de promover un ambiente de respeto por las distintas visiones de mundo, trabajando al mismo tiempo el conocimiento transmitido por la óptica del extrañamiento, deshabilitando zonas de confort. 


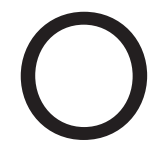

No Brasil, os termos "protestante", "evangélico" e "crente" são empregados por muitos autores indistintamente, exigindo alguns esclarecimentos sobre a terminologia adotada neste trabalho.

Alguns autores, como Cunha (2007), esclarecem que o termo "protestante", raramente, tem sido empregado por esses religiosos para se referirem a si mesmos. Os missionários norte-americanos conservadores que aqui chegaram a partir do início do século $X X$ autodenominavam-se "evangelicals", o que, aportuguesado, resultou em "evangélicos". O termo "crente", já desgastado e empregado de modo pejorativo, foi substituído então pela nova designação. Desse modo o termo evangélico é empregado aqui em sua concepção mais abrangente, englobando todas as igrejas oriundas da Reforma do século XVI. Os membros da Igreja Adventista do Sétimo Dia

são um grupo religioso originado na segunda metade do século XIX, nos Estados Unidos, a partir de diversos grupos protestantes que aguardavam então o retorno iminente de Jesus Cristo e o fim dos tempos (NUMBERS, 2006)

PONDO-SE AO ESPERADO POR MUITOS, O ADVENTO DA MODERNIDADE E DE TODAS as suas instituições não assistiu ao declínio da importância das manifestações religiosas. No Brasil, nas décadas de 1970 e 1980, havia poucos estudos sociológicos dedicados a explicar o significado do crescimento pentecostal. ${ }^{1}$ Muitos dos pesquisadores, então voltados para as grandes questões econômicas e políticas, não consideravam a análise das experiências religiosas pentecostais como um fenômeno digno de atenção, sendo encaradas como "fenômenos passageiros, uma vez que as religiões deveriam decrescer diante da modernização tecnológica em curso e em virtude do desejo de aperfeiçoamento das instituições democráticas do país" (NOVAES, 1999, p. 125).

Duas décadas depois, o pentecostalismo dobrou o número de seus membros no Brasil e não pôde mais ser ignorado, fazendo-se presente em diversos setores da vida pública, da política aos meios de comunicação de massa, difundindo ideias e modelos de comportamento que tiveram desdobramentos nos setores mais diversos da sociedade brasileira, tais como educação, saúde, política, lazer, religião, consumo e sexualidade. Nenhum outro grupo organizado experimentou no nosso país tamanho sucesso em um intervalo de tempo tão curto desde o seu surgimento nos Estados Unidos, há pouco mais de cem anos. Uma transformação dessa magnitude nessa reduzida dimensão temporal certamente passou a demandar um melhor entendimento por parte dos investigadores de diversas áreas e instalou desafios e potencialidades inéditos no cotidiano dos profissionais envolvidos de alguma maneira com as consequências de sua influência crescente. Dentre eles se encontram os professores de ciências e biologia, uma vez que a teoria evolutiva vai de encontro às interpretações criacionistas da origem e 
diversificação da vida, especialmente da espécie humana, defendida por essa e outras vertentes do protestantismo conservador que apresentam interpretações doutrinárias fundamentalistas.

Embora algumas das ideias que compõem o ideário do criacionismo cristão encontrem suas origens no conjunto de histórias e representações simbólicas herdadas do judaísmo, sua versão contemporânea, como um movimento organizado, representa em grande parte um fenômeno característico dos Estados Unidos que foi exportado para o resto do mundo (SCOTT, 2006), inclusive o Brasil. Sendo um subproduto das vertentes que compõem o literalismo bíblico protestante, bem como de suas derivações - como, por exemplo, o Movimento Adventista o criacionismo cresce sempre que visões religiosas cristãs de matrizes doutrinárias fundamentalistas se tornam populares (MATZKE, 2010). Desse modo, o conjunto de transformações ocorridas no cenário religioso brasileiro nas últimas quatro décadas representou um dos principais caminhos para a expansão das ideias criacionistas.

Esse conflito com ideias religiosas, se não representa algo novo, parece ter adquirido, nas últimas quatro décadas, uma nova roupagem, caracterizada pela disputa com afinco por novos espaços, como, por exemplo, as salas de aula da educação básica pública e privada, resultando em conflitos frequentes com as ideias evolutivas (SEPULVEDA; EL-HANI, 2009; RAZERA; NARDI, 2001), na produção de material didático próprio para o ensino de ciências e biologia, na multiplicação de estratégias de divulgação de suas ideias por meio de congressos, palestras, vídeos e endereços eletrônicos (SOUZA, 2009) e em sua mais recente atuação na esfera política, procurando modificar a legislação para permitir o ensino do criacionismo (MARTINS, 2001).

Outra implicação desse fenômeno para o ensino de ciências e biologia pode ser observada no número crescente de professores vinculados a várias dessas igrejas, o que muitas vezes resulta em conflitos internos sobre o ensino de determinados conteúdos, podendo interferir na qualidade do ensino e na desenvoltura com que conseguem abordar certas questões, como as associadas à evolução biológica (LICATTI, 2005). Como mostrado mais adiante, futuros professores de ciências e biologia, em especial aqueles oriundos de segmentos religiosos fundamentalistas, apresentam forte influência de suas visões religiosas ao longo de sua formação inicial, ora explicitando seus diversos conflitos, ora encontrando na universidade pública o espaço para reafirmação da impossibilidade de se apropriarem dos conceitos evolutivos. Estudos realizados por Sepulveda e El-Hani (2004), Dorvillé (2010) e Teixeira e Andrade (2014) documentaram esses conflitos e nos ajudam a reconhecer que há implicações educacionais na leitura literal da Bíblia que não se circunscrevem ao privado, mas que afetam peremptoriamente o direito de alunos de 
escolas públicas a uma formação que não censure ou limite a qualidade da abordagem dos conteúdos biológicos.

Desse modo, entender que o ensino de evolução e sua maior ou menor aceitação envolvem não apenas questões específicas associadas aos conteúdos da ciência de referência, lidando na verdade com questões de muitas áreas e abordagens diferentes, é outro aspecto que merece ser ressaltado neste trabalho. Trata-se, portanto, de um ponto de partida para pensar qualquer ação menos superficial sobre o ensino de ciências e biologia, com chances maiores de apresentar resultados mais promissores. Argumenta-se, assim, que alguns dos subsídios fornecidos a partir da análise aqui apresentada possam vir a ser produtivos, como parte do conteúdo necessário à formação inicial e continuada de professores de ciências e biologia, contribuindo igualmente para a construção de uma abordagem mais crítica do ensino das disciplinas dessa área.

O propósito deste artigo é provocar reflexões que evidenciem historicamente as influências das matrizes criacionistas norte-americanas e o movimento expansionista desse ideário. Assim, procura-se examinar as transformações do criacionismo ao longo da história recente, suas estratégias de sobrevivência e suas derrotas, tomando como referência a matriz criacionista norte-americana para pensar sua penetração no contexto brasileiro. Essa análise, associada a investigações teórico-empíricas sobre essa temática, permite tecer reflexões sobre suas implicações para a formação docente e o ensino de ciências e biologia hoje no Brasil.

\section{MATRIZES CRIACIONISTAS}

Entender as matrizes de ideias que influenciaram o protestantismo brasileiro envolve abordar suas origens norte-americanas. Como enfatiza Mendonça, “o protestantismo brasileiro segue sendo uma projeção do protestantismo norte-americano” (2002, p. 13). Portanto, os vários tipos de igrejas evangélicas encontradas no Brasil são, em sua maioria excluindo apenas as igrejas de imigração étnica, como a de luteranos alemães, por exemplo -, o resultado desse processo histórico, carregando as marcas inerentes dessa constituição peculiar. Este estudo argumenta que a influência do pentecostalismo norte-americano sobre o brasileiro não se circunscreve apenas ao domínio do privado, reproduzindo em nosso país sua ingerência no contexto educacional, tanto na educação básica como na formação docente, na forma de uma estratégia de poder que ameaça seriamente o princípio republicano de uma educação laica.

O criacionismo cristão encontra as suas principais justificativas doutrinárias contemporâneas no movimento fundamentalista oriundo dos Estados Unidos. É claro, como relata Mayr (2006), que, desde a publicação de A origem das espécies, alguns dogmas da cristandade foram desafiados, tais como: a crença em um mundo constante; o surgimento 
de cada um dos seres vivos a partir da ação direta de um Criador, sendo, portanto, cada um deles fixo e imutável; a existência de um propósito em tudo que faz parte do mundo natural; e, finalmente, a crença na posição diferenciada do homem em relação às demais formas de vida. No entanto, boa parte do cristianismo foi capaz de incorporar as novidades trazidas por essas descobertas, reservando-se apenas o direito de rejeitar o naturalismo filosófico. Em 1996, por exemplo, a Igreja Católica, na figura do papa João Paulo II, defendeu a evolução do ser humano a partir de outras espécies de primatas, reservando, porém, à intervenção divina a criação da alma, a qual entraria nos corpos de nossa espécie apenas ao final desse processo (SCOTT, 2004). Mais recentemente, o papa Francisco afirmou que a teoria da evolução não é incompatível com a fé (VEIGA; BRANDÃO, 2014). Em época muito anterior, na década de 1880, teólogos protestantes liberais norte-americanos como John Bescon, Henry Ward Beecher e John Fiske defendiam que não poderia haver oposição entre ciência e religião, estando abertos tanto à crítica ao literalismo bíblico como às inovações científicas, dentre elas a evolução biológica. Tais inovações poderiam desfazer algumas das certezas anteriores, mas, a longo prazo, levariam a um entendimento mais profundo dos textos sagrados. Todos os três consideravam o divino como imanente ao mundo, e não como uma entidade separada, e, dessa forma, a atuação dos processos evolutivos na natureza seria uma prova da incessante preocupação de Deus com sua criação (ARMSTRONG, 2001).

Para a comunidade científica dos Estados Unidos, já na década de 1870, a evolução era considerada, com raras exceções, ${ }^{2}$ um fato além de qualquer questionamento, havendo ainda grande debate quanto à adequação da seleção natural como seu principal mecanismo de ação. Os tempos não eram nada fáceis para os literalistas, e, como relata Numbers (1998), muitos desses círculos aceitavam a antiguidade do nosso planeta revelada pelas evidências paleontológicas, desenvolvendo uma série de adaptações para que o texto bíblico ainda pudesse ser lido como verdade absoluta. Desse modo, mesmo os teólogos conservadores, nesse período de realce das noções de progresso, ciência e desenvolvimento, tiveram que alterar alguns de seus pontos de vista para resguardar sua influência. Assim, surgiram os criacionistas que interpretaram os dias da criação descritos no Gênesis como as eras geológicas registradas pela paleontologia, mais conhecidos como "criacionistas do dia-era” (day-age creationists). Outros inseriram uma série de catástrofes e novas criações em um intervalo que acreditavam existir entre os dois primeiros versos do Gênesis, sendo conhecidos pelo nome de "criacionistas do intervalo" (gap creationists). Por fim, um terceiro grupo aceitava a maior parte das contribuições científicas, como a distribuição sucessiva dos estratos fósseis em camadas geológicas de eras distintas, uma vez que defendiam a ideia de que Deus havia criado os diferentes "tipos" de seres vivos Louis Agassiz (1807-1873). Segundo Ernest Mayr (1998), esse naturalista, nascido na Suíça francesa, viveu nos Estados Unidos, onde realizou diversos estudos e empreendimentos científicos, tornando-se uma resistência às ideias evolutivas nesse país. 
sequencialmente, de modo independente, do mais simples ao mais complexo, nas diferentes eras. Cada um deles seria capaz de experimentar evolução apenas no interior do seu “tipo”. Baseado nessa concepção criacionista carregada de conotações de progresso, tal grupo passou a ser reconhecido pelo nome de "criacionistas progressistas" (progressive creationists). Desse modo, como enfatizam Scott (2004) e Numbers (2006), o conceito de criacionismo não representa uma categoria monolítica, abrigando em seu interior um continuum de posições que envolvem concessões maiores ou menores às descobertas científicas.

Todos os grupos anteriores diferem dos criacionistas stricto sensu por reconhecerem a antiguidade de nosso planeta, sendo por essa razão denominados de criacionistas da Terra antiga (Old Earth Creationists - OEC), em oposição aos primeiros, conhecidos pela alcunha de criacionistas da Terra jovem (Young Earth Creationists - YEC). Ao final do século XIX, os únicos cristãos a defenderem o aparecimento recente da vida na Terra e a atribuírem o registro fóssil à ação do dilúvio eram os adventistas, uma situação que se alteraria profundamente nas décadas seguintes (NUMBERS, 2006).

Nesse período, a interpretação crítica do texto bíblico, denominada criticismo superior, era considerada um inimigo maior da ortodoxia bíblica do que a evolução. Nos primeiros anos do século XX, como registra Moore (2001), poucos livros de história natural não mencionavam a palavra "evolução", enquanto outros dedicavam capítulos inteiros ao assunto. Essa coexistência deixaria de ser pacífica nos anos seguintes, assumindo o caráter de cruzada antievolucionista, embora todas as tentativas de acomodação descritas anteriormente nunca tenham desaparecido por completo. Dessa feita, o literalismo bíblico e o antievolucionismo passariam a ser encarados nas décadas seguintes como sinônimos por muitos evangélicos, como se assim fosse desde o início dos tempos.

A Primeira Guerra Mundial trouxe um sentimento de assombro e de derrota da civilização para boa parte da população do mundo, solapando sobremaneira a visão positiva que muitos ainda tinham da ciência. O resultado foi um reforço do pensamento religioso fundamentalista nos Estados Unidos, aparentemente corroborado pelo fato de um mesmo país, a Alemanha, ser simultaneamente a sede de um militarismo expansionista e do criticismo bíblico acadêmico. Além disso, segundo os fundamentalistas norte-americanos, as ideias de evolução biológica também estavam por trás das concepções de eugenia e superioridade racial germânicas, as quais seriam, segundo sua interpretação, a tradução em termos concretos da noção de sobrevivência dos mais fortes, cabe dizer, um conceito que nunca foi formulado por Darwin. A disseminação do criacionismo fundamentalista foi o resultado do choque entre uma nova era que se anunciava, com suas inovações tecnológicas e econômicas, e 
a resposta que a ela davam as populações que experimentavam esse processo de modo marginal e periférico. Uma resposta assustada que via no conhecimento científico não um arauto de dias melhores, mas um instrumento de dominação do homem comum por interesses econômicos e por elites intelectuais minoritárias que o desprezavam. Nas palavras de William Jennings Bryan, importante líder criacionista norte-americano: "A mesma Ciência que havia fabricado gases venenosos e sufocado soldados está pregando que o homem possui uma ancestralidade selvagem e eliminando o milagroso e o sobrenatural da Bíblia” (NUMBERS, 2006, p. 56). Como ressalta Ruse (2006, p. 266), os crentes se ressentiam não da mudança evolucionária em si, mas do contexto em que tal mudança era apresentada. Moore (2000) conclui, então, que o criacionismo, nos Estados Unidos, é uma resposta ao que era percebido como uma perda de valores morais associada aos novos tempos. Como destaca Armstrong (2001, p. 168), “há desespero na Teologia de Princeton”. Prova disso é a declaração de Charles Hodge, catedrático de teologia dessa universidade, ao afirmar, em 1874, na obra intitulada What is Darwinism? [O que é darwinismo?], que "a religião tem de lutar por sua existência contra uma vasta classe de cientistas” (apud ARMSTRONG, 2001, p. 168). Esse livro representou o primeiro ataque religioso sistemático à teoria evolutiva. Hodge afirmava que Deus nos havia dotado de "intuições infalíveis", e, se os ensinamentos de Darwin as contradiziam, sua hipótese seria falsa e deveria ser rejeitada (apud ARMSTRONG, 2001).

É importante frisar que, nos Estados Unidos, o número de matrículas no ensino médio havia saltado de 200.000, em 1890, para mais de dois milhões, em 1920 (RUSE, 2006). A maioria desses alunos, chegada recentemente de uma realidade rural, atingia pela primeira vez um grau de escolarização nunca alcançado por seus pais. Era natural, portanto, que o interesse a respeito do conteúdo do ensino ministrado fosse uma preocupação mais intensa do que em épocas anteriores. A escola, desde então, passou a ser vista como um espaço privilegiado a ser disputado pelos criacionistas. Apesar das enormes diferenças entre as sociedades norte-americana e brasileira, é impossível não perceber um paralelo entre as duas realidades, vivenciadas, porém, em momentos bem distintos de suas histórias.

A solução para esses tempos incertos, segundo os líderes religiosos criacionistas, se encontrava no interior das comunidades religiosas e em uma fé que promovesse respostas simples, à sombra da autoridade absoluta do texto bíblico interpretado como verdade literal. Tudo que significasse retorno aos antigos valores, desestruturados pela ganância e velocidade das transformações dos novos tempos, encontrava a receptividade de uma grande audiência. Não sem motivo, portanto, parte significativa das massas se alinhou às perspectivas fundamentalistas nos Estados Unidos, e a teoria geral de evolução das espécies passou a ser 
símbolo, em meio a várias outras, das ideias que oprimiam os estilos tradicionais de boa parte da classe trabalhadora do país. Estava pronto o cenário para o primeiro movimento criacionista organizado, havendo várias lideranças religiosas que capitaneavam esse descontentamento, inclusive nos comitês locais que controlavam o currículo escolar.

Entre 1910 e 1915, foi publicada nos Estados Unidos uma série de livretos escritos por alguns dos teólogos conservadores americanos e britânicos de maior destaque, denominados The fundamentals - A testimony of the truth [Os fundamentos - Um testemunho da verdade]. Segundo seus editores, essas obras foram publicadas com a intenção de conter a erosão moral que assolava as igrejas norte-americanas. Nelas são encontrados alguns dos princípios doutrinários tradicionais que deveriam nortear a fé do protestantismo conservador, dentre eles a inerrância da Bíblia e a criação direta do mundo e do homem ex nihilo a partir da divindade (em oposição à evolução biológica) (RUTHVEN, 2007, p. 7). O crescimento do fundamentalismo no interior das igrejas foi, na maioria dos casos, uma reação da base ao que muitos consideravam o elitismo dos seminários, distanciados da cultura e das crenças dos fiéis comuns, resultando em inúmeras disputas violentas e cisões entre presbiterianos, batistas, luteranos e metodistas (RUTHVEN, 2007, p. 12).

Como resultado da campanha nacional iniciada por Bryan, em 1921, na qual percorreu o país dando palestras para auditórios sempre lotados, em 1922, o Estado do Kentucky lançou o primeiro movimento pela erradicação do ensino de evolução nas escolas públicas, sendo seguido por iniciativas semelhantes em mais de vinte estados, com a promulgação de leis antievolucionistas. A resposta não demorou, e veio na forma de uma das batalhas jurídicas mais importantes da história norte-americana, no evento conhecido como Monkey Trial [Julgamento do Macaco], assim denominado em alusão à origem do ser humano a partir de outros primatas. Em 1925, logo após a aprovação da lei no Tennessee, um jovem professor de 24 anos de uma escola secundária, John Thomas Scopes, declarou publicamente que havia ensinado evolução aos seus alunos, sendo por isso indiciado. O resultado do julgamento até hoje é uma questão controversa. Alguns afirmam que nele foi indicada a fraqueza da argumentação criacionista, sendo a imagem pública dos antievolucionistas seriamente abalada (SOUZA, 2009, p. 49), com sua exposição pela mídia como caipiras ignorantes e fanáticos religiosos desprovidos dos conhecimentos inerentes à modernidade. Outros, entretanto, alegam que se tratou de uma vitória de Pirro, uma vez que, buscando agradar cada vez mais o mercado editorial crescente, as editoras de livros didáticos optaram por retirar das edições seguintes de suas publicações qualquer menção à evolução biológica (GOULD, 2002, p. 110; MOORE, 1998, p. 576). 


\section{O CRIACIONISMO "EVOLUI"}

Uma reviravolta no ensino de ciências nos Estados Unidos ocorreu quando, em 1957, a União Soviética lançou o primeiro satélite espacial, o Sputnik, alarmando as autoridades norte-americanas, que se viram em plena Guerra Fria na incômoda posição de segunda potência na corrida espacial. Em busca de razões que explicassem esse atraso, o governo, pressionado pela opinião pública e pela comunidade científica - em disputa com educadores de inspiração deweyana aos quais acusavam pelo empobrecimento dos conteúdos científicos no currículo -, elegeu a qualidade da educação científica do país como a principal causa, traçando como meta a sua completa reformulação. Foram elaboradas propostas curriculares para todas as áreas científicas do ensino secundário, e a que se dedicou ao ensino de biologia foi o Biological Sciences Curriculum Study - BSCS -, iniciado em 1957, tendo como objetivo produzir novos materiais curriculares. Dentre eles, os que mais se destacaram foram livros didáticos - em três versões, amarela, verde e azul ${ }^{4}$ - que priorizavam a atualização e o métodos de ensino em bases experimentais. A elaboração desses materiais foi liderada por cientistas renomados das mais diversas especialidades, com finalidades explícitas de estimular nos alunos o apreço pela ciência e o direcionamento para as carreiras científicas (MARANDINO; SELLES; FERREIRA, 2011).

As três versões do BSCS, publicadas em 1963, adotaram a evolução biológica como eixo unificador fundamental das ciências biológicas (SCOTT, 2004; MOORE, 2001). Graças ao apoio do governo federal, que garantia a sua distribuição independente do retorno comercial, ao interesse crescente em uma boa educação, à qualidade do material e à sua pedagogia inovadora, os BSCS rapidamente ganharam metade do mercado de livros didáticos do país (LARSON, 2003, p. 95), inclusive nos três estados norte-americanos que tinham leis contrárias ao ensino de evolução. Em tempos de destaque da ciência, de uma economia que crescia a taxas extremamente altas, diante da necessidade crescente de qualificação da mão de obra e da importância dos avanços tecnológicos na vida de todas as pessoas, foram cada vez maiores as pressões da população sobre os comitês escolares locais pela adoção dos novos livros. Embora muitos fossem contra o ensino de evolução - e inúmeras manifestações tenham sido publicadas em jornais de todos os estados -, essa discordância entrava em conflito com a possibilidade de seus filhos receberem uma educação de qualidade inferior.

Resultante da intenção de cientistas notáveis, com espaços privilegiados no American Institute of Biological Sciences - AIBS -, no periódico American Biology Teacher - ABT - e em setores econômicos poderosos de política científica, como a National Science Foundation - NSF -, após décadas de banimento, o ensino de evolução voltou a fazer parte dos livros escolares de biologia. Segundo Larson (2003), tratava-se do rompimento 
de um acordo tácito entre os editores de livros didáticos e os segmentos contrários à evolução, não apenas nas igrejas e nas famílias que as frequentavam, mas também - e principalmente - nos representantes que tinham assento nos comitês escolares locais.

Com efeito, os criacionistas não demoraram a reagir. Os tempos, contudo, eram outros. Se, no julgamento de Scopes, a base de ação contra a evolução era inteiramente centrada em motivos explicitamente religiosos, tais como seu caráter não bíblico e seu potencial supostamente capaz de afastar os jovens da fé, agora a cultura científica era uma força muito mais poderosa, e os criacionistas procuraram explorar essa respeitabilidade (SCOTT, 2004). Se a evolução biológica tinha então o direito de ser ensinada nas escolas - algo consensual nessa nova configuração de forças instaurada pela reforma da educação científica pós-Sputnik -, a perspectiva bíblica também o tinha. Esse era o argumento que se fazia presente, numa completa inversão de posições ao que fora observado no caso de Scopes (LARSON, 2003, p. 100), em que o ponto de partida era o combate à legitimidade inicial do ensino dos conteúdos evolucionistas. A defesa aberta do ensino religioso nas escolas públicas, no entanto, teria pouca chance de sucesso, pois seria considerada inconstitucional. Porém, se pudesse ser apresentado também como ciência, o criacionismo poderia pleitear o status de visão científica alternativa, merecendo assim lugar no currículo de ciências. Em tempos em que o conhecimento científico representava um capital fortemente valorado pela maior parte da sociedade, reivindicar a legitimidade científica mantendo a conotação religiosa da mensagem significava procurar auferir as benesses dos dois campos. O criacionismo estava de volta, agora não como uma crença religiosa, mas como uma explicação científica alternativa (SCOTT; MATZKE, 2007). Além disso, sob esse novo aspecto, ele facilitava a acomodação de formas de pensamento distintas, silenciando conflitos, desmontando dilemas e desestimulando questionamentos. De maneira inédita ele pretendia revelar os fundamentos científicos da defesa da fé cristã, fornecendo apoio à Bíblia como palavra divina literal. Assim, a certeza da fé cristã poderia ser também revelada por fatos comprováveis e métodos objetivos (WILLIAMS, 1983).

Na década de 1960, na esteira do sucesso editorial dos BSCS, novos livros com conteúdo evolutivo passaram a ser produzidos nos mesmos moldes ou reintroduziram os conteúdos evolutivos outrora removidos, gerando alguns impasses. Muitos desses livros foram comercializados, mas sua adoção entrava em confronto muitas vezes com leis estaduais ainda vigentes contrárias ao ensino da evolução. Assim ocorreu, em 1965, no Arkansas, com a professora de biologia Susan Epperson, que, apoiada pela American Civil Liberties Union - ACLU - e pela National Education Association - NEA -, entrou com uma ação contra o Estado em defesa da liberdade de expressão, uma vez que a utilização de um 
livro de biologia com conteúdos evolutivos era contestada por uma lei local (PARKER, 1981). O caso foi para a Suprema Corte em 1968, quando a decisão final favorável foi anunciada, a qual, além de abrir um precedente jurídico importante que tornava cada uma das leis estaduais contra o ensino de evolução inconstitucional (SCOTT; MATZKE, 2007), inspirou muitos outros movimentos.

O contra-ataque dos criacionistas não tardou. Porém, traçar diretrizes a respeito do conteúdo das disciplinas escolares e não contar com livros didáticos que representassem o seu ponto de vista era um ponto fraco que os criacionistas não deixaram de tentar corrigir rapidamente. Procurando fazer frente ao BSCS, em 1970, foi publicado o livro Biology: a search for order in complexity [Biologia: uma busca por ordem na complexidade], destinado a escolas secundárias norte-americanas. Na prática, foram vendidos poucos exemplares, e o livro enfrentou dificuldades legais em vários estados em virtude de sua insofismável natureza religiosa (SCOTT, 2004). Nova tentativa foi feita com o livro Scientific creationism [Criacionismo científico], em 1974, o qual passou pelos mesmos problemas do livro anterior.

Ainda em 1969, o Comitê Estadual de Educação do Texas retirou dois livros BSCS da lista de didáticos aprovados para uso nas escolas públicas, e, um ano depois, declarou que todos os textos que abordassem evolução deveriam caracterizá-la apenas como uma teoria. Esse emprego do termo "teoria” é inteiramente derivado do significado que essa palavra assume no dia a dia e inteiramente diverso daquele que assume na ciência. Assim, quando falamos em teoria, estamos fazendo alusão a "uma explicação bem fundamentada de algum aspecto do mundo natural que seja capaz de incorporar fatos, leis, inferências e hipóteses testadas" (SCOTT, 2004, p. 14). De qualquer modo, esse passou a ser um dos principais motes criacionistas junto com a defesa do ensino da teoria evolutiva associado ao ensino do criacionismo científico, em benefício de uma visão mais “equilibrada” sobre o assunto.

Em 1981, o Arkansas foi o primeiro estado a aprovar uma lei que garantia tempo igual para o ensino do criacionismo e da evolução, a qual foi contestada por uma ação liderada pelo pastor William MacLean, à qual se juntaram outros religiosos, contribuindo para desqualificar o argumento de que a oposição à lei significava um ataque à religião. Em 1982, o caso foi julgado pela Suprema Corte, que considerou o ensino do criacionismo científico como inconstitucional, uma vez que se tratava "simplesmente de um esforço para introduzir a versão bíblica da Criação no currículo das escolas públicas” (LARSON, 2003, p. 163). O juiz também declarou que os criacionistas "não podem adequadamente descrever a metodologia usada como científica se eles começam com uma conclusão e se recusam a alterá-la independente das evidências que apareçam durante o curso da investigação” (SCOTT, 2008). 
Cansados de todas as derrotas sofridas nos tribunais norte-americanos, os criacionistas se empenharam, a partir do final da década de 1980, em remodelar uma vez mais sua mensagem, retirando dos seus textos todas as referências a palavras como "criação", "criador" e "criacionismo" (NUMBERS, 2006). Ao mesmo tempo, seu discurso deixou de defender o ensino simultâneo da teoria evolutiva e do criacionismo científico e passou a argumentar em favor do ensino do evolucionismo aliado ao das "alternativas científicas à evolução" ou ao das "evidências contra a evolução". Scott (1997) destaca que, como a essência do criacionismo científico sempre consistiu em críticas à evolução, foi fácil repaginá-lo como "evidência contra a evolução". Uma das principais palavras de ordem do movimento passou, então, a ser a defesa do "ensino da controvérsia”, como se existisse alguma no interior da comunidade científica a respeito do poder explicativo da evolução. Como apontado por Apple (2008, p. 329-330): “os proponentes do Desenho Inteligente foram bastante espertos linguisticamente”. Baseando seus argumentos na linguagem do "equilíbrio" e do "ensino de todos os lados", eles foram capazes de estrategicamente empregar a linguagem do liberalismo para dar suporte às conviç̧ões religiosas que em geral podem não ser qualificadas como adequadas sob o guarda-chuva da ciência legítima.

O movimento mais bem-sucedido nesse sentido é conhecido pela denominação de intelligent design [desenho inteligente]. Procurando apresentar-se como uma alternativa científica bem mais sofisticada do que o criacionismo científico, os membros desse movimento apresentavam, entre seus principais teóricos, indivíduos com credenciais acadêmicas reconhecidas, fornecidas por instituições seculares. Além disso, para que seu discurso pudesse pleitear legitimidade no campo da ciência, seria necessário que ele fosse embasado, como no caso de qualquer teoria científica, em alguns conceitos básicos. Desse modo, os acadêmicos desse movimento se propuseram a elaborá-los, cercando-os de todas as supostas evidências empíricas. Um desses conceitos é o de "complexidade irredutível”, a ideia de que estruturas biológicas extremamente complexas não poderiam resultar de processos naturais, devendo ser produzidas pela ação de alguma "inteligência” ou "força”, cuja natureza evitavam mencionar. Na verdade não se tratava de uma ideia nova, mas uma reedição do argumento do teólogo do século XIX William Paley, que afirmava que a existência de Deus poderia ser comprovada pela complexidade encontrada na natureza (SOUZA, 2009). Paley explicava tal fato usando a analogia de um relógio encontrado em um descampado. Claramente sua existência seria uma prova - por sua intrincada estrutura de inúmeros componentes funcionais interligados de modo ordenado - da existência de um design [desenho], e, por consequência, de um designer [projetista, arquiteto], o relojoeiro que o havia montado. 
Buscando, uma vez mais, penetrar no sistema de educação pública norte-americano, os criacionistas, capitaneados agora pelos proponentes do “desenho inteligente”, não demoraram a preparar seu próprio livro didático, dessa vez recomendado para ser usado como livro texto suplementar para alunos do ensino médio. Lançado em 1989, of Pandas and people: the central question of biological origins [Sobre pandas e pessoas: a questão central das origens biológicas] foi o primeiro livro a empregar explicitamente o termo “desenho inteligente” em suas versões finais. Todas as versões originais que continham referências ao criacionismo foram substituídas em edições posteriores, demonstrando claramente a vinculação entre o "desenho inteligente" e o criacionismo científico (BRANCH; SCOTT, 2009). Embora o uso do livro tenha sido, em um primeiro momento, aprovado em algumas escolas como resultado de pressão sobre os comitês escolares locais, após sucessivas batalhas jurídicas, seu destino foi igual ao de seus antecessores (SCOTT; MATZKE, 2007).

A maior de todas as ações jurídicas envolvendo a teoria do “desenho inteligente” ocorrida até o momento se deu em 2005, na Pensilvânia. Nela, Tammy Kitzmiller e dez outros pais moveram uma ação contra o Comitê Escolar de Dover, devido à decisão de obrigar as escolas do distrito a lerem uma declaração antes das aulas de biologia. Essa declaração afirmava que a evolução era apenas uma teoria que deveria ser criticamente analisada e introduzia o "desenho inteligente" como teoria alternativa, recomendando a leitura de of pandas and people para maiores esclarecimentos a respeito do "desenho inteligente" e das falhas na teoria evolutiva (BRANCH; SCOTT, 2009). O juiz do caso proferiu em sua sentença que o "desenho inteligente" constituía uma forma de criacionismo, e que, por essa razão, não merecia espaço nas escolas públicas (SCOTT, 2006).

O movimento cresceu, transferindo sua sede para uma nova instituição não vinculada diretamente a atividades religiosas, o Discovery Institute, uma organização conservadora voltada à promoção de ideias relacionadas ao livre mercado e às liberdades individuais. Deixando de lado as espinhosas questões relacionadas ao modo como teria ocorrido a criação, o “desenho inteligente" tornou-se uma "grande tenda”, reunindo em seu interior uma variedade de antievolucionistas, de criacionistas da Terra jovem a criacionistas progressistas (NUMBERS, 2006, p. 377).

\section{CRIACIONISMO E SUAS IMPLICAÇÕES PARA A FORMAÇÃO DOCENTE E O ENSINO DE CIÊNCIAS E BIOLOGIA NO BRASIL}

Guardadas as devidas diferenças entre a realidade encontrada aqui e nos Estados Unidos, Martins (2001) caracteriza o criacionismo brasileiro como “em expansão”, e Souza (2009, p. 12) afirma que, em nosso país, 
"os movimentos criacionistas começam a se organizar de forma sistemática”. Vários sítios de igrejas evangélicas na internet se dedicam a retransmitir as ideias de algumas das principais vozes do criacionismo, e editoras vinculadas a denominações religiosas traduzem para o português muitas de suas publicações.

A presença de organizações empresariais envolvidas em sua promoção, financiando a tradução, publicação e distribuição de livros e material didático de apoio para utilização em algumas escolas confessionais brasileiras (DORVILLÉ, 2010; SOUZA, 2009), bem como promovendo as viagens de palestrantes pelo país e recebendo seguidas visitas de lideranças internacionais ligadas ao setor, é cada vez mais frequente. Antes restrito apenas à esfera dos adventistas, o criacionismo avança sobre as denominações evangélicas, sendo evidente o estreitamento das relações e a colaboração com organizações internacionais. Embora boa parte dos evangélicos não se ocupe diretamente dessas questões, em virtude do literalismo bíblico de seus ensinamentos, a oposição à evolução biológica se faz sempre presente, ainda que de modo difuso. Percebendo um campo receptivo nesse sentido, o pastor Silas Malafaia, da Assembleia de Deus Vitória em Cristo, lançou o livro Criação X Evolução: Quem está com a Verdade?, em que afirma haver um "interesse satânico [...] [para] cegar o entendimento dos incrédulos para que eles não tenham conhecimento sobre a verdade e sejam libertos por ela" (MALAFAIA, 20095 , p. 33, apud TEIXEIRA, 2014).

Destaca-se, ainda, a realização periódica de simpósios e seminários "científicos" com apresentação de trabalhos com pontos de vista declaradamente criacionistas, como o "Seminário Filosofia das Origens", promovido pela Sociedade Criacionista Brasileira - SCB -, fundada em 1972 em Brasília por adventistas. A SCB também promove regularmente, de acordo com Souza (2009), um evento denominado "Seminário Criacionista de Capacitação de Professores”. Outra organização criacionista é a Associação Brasileira para a Pesquisa da Criação - ABPC -, fundada em 1979 por evangélicos em Belo Horizonte, que já trouxe cinco vezes ao Brasil o bioquímico americano Duane Gish, importante representante internacional do criacionismo. Além disso, nota-se a atuação do "desenho inteligente" no Brasil, que realizou seu primeiro congresso nacional em 2014, no qual foi criada a Sociedade Brasileira do Desenho Inteligente.

Na educação básica, o caso emblemático do Rio de Janeiro repercutiu amplamente. A lei n. 3.459, de autoria do deputado Carlos Dias - ligado à arquidiocese e militante católico da Renovação Carismática (CUNHA, 2006) - e sancionada pelo então governador Anthony Garotinho, em março de 2002, abriu caminho para que alguns dos quinhentos professores contratados para ministrar aulas de religião nas escolas estaduais manifestassem sua intenção de incluir o criacionismo como parte do conteúdo de sua disciplina. Essas notícias provocaram reações da comunidade científica. Aproveitando a ocasião da realização 
do primeiro concurso do estado para professores de religião, sua sucessora e esposa, a também ex-governadora Rosinha Garotinho, manifestou sua opinião em defesa do criacionismo bíblico e descrença diante do paradigma da evolução biológica das espécies. Rosinha e seu marido são presbiterianos e têm em parte dos evangélicos uma importante base eleitoral, lançando mão com frequência de discursos de cunho religioso voltados para a defesa da fé e da moral cristãs. Alguns autores, como Schünemann (2008), viram nesse episódio uma evidência das diferenças do grau de relevância do movimento criacionista brasileiro em comparação com o norte-americano, uma vez que nos Estados Unidos o ensino do criacionismo nas escolas através do ensino religioso há muito teria sido abandonado pela maioria dos grupos. Nessa mesma linha, em 13 de novembro de 2014, o deputado federal Marco Feliciano (PSC-SP), pastor da igreja Catedral do Avivamento, uma igreja ligada à Assembleia de Deus, encaminhou ao Congresso Nacional o Projeto de Lei n. 8.099/2014, que tem como objetivo tornar obrigatório o ensino do criacionismo na educação básica pública e privada do país, gerando manifestações de repúdio por parte de diversas entidades, como a Associação Brasileira de Ensino de Biologia - SBEnBIO - e a Associação Brasileira de Pesquisa em Educação em Ciências - Abrapec (ASSOCIAÇÃO BRASILEIRA DE ENSINO DE BIOLOGIA, ASSOCIAÇÃO BRASILEIRA DE PESQUISA EM EDUCAÇÃO EM CIÊNCIAS, 2014).

Desse modo, as discussões relacionadas à presença do criacionismo no espaço escolar brasileiro - tanto em relação às conviç̧ões pessoais de alunos e professores, com seus reflexos no ensino de ciências e biologia, como em relação à sua dimensão política de ingerência no campo educacional por movimentos religiosos organizados - encontram-se na ordem do dia, reunindo as condições necessárias para se fazerem cada vez mais presentes. Acreditamos, portanto, que uma parte importante da formação inicial e continuada desses professores deva incluir as discussões que envolvem as relações entre os conteúdos específicos da ciência de referência e os dilemas e conflitos que sua interação com outras visões de mundo são capazes de proporcionar.

Vários trabalhos apontam para as dificuldades enfrentadas por licenciandos e professores da educação básica na relação entre o ensino de evolução e posições religiosas criacionistas dos próprios entrevistados ou por parte dos seus alunos (SEPULVEDA; EL-HANI, 2004; TIDON; LEWONTIN, 2004; FONSECA, 2008; TEIXEIRA; ANDRADE, 2014). Aplicando um questionário a 245 licenciandos em Ciências Biológicas de todos os períodos de uma mesma instituição, Dorvillé (2010) identificou a presença de visões criacionistas, especialmente entre os alunos evangélicos (23,4\% dos estudantes). Os posicionamentos dos alunos em relação a quatro afirmações ou questionamentos do instrumento foram emblemáticos e merecem uma análise mais detalhada. 
Diante da afirmação "Todos os seres vivos descendem de uma única forma de vida”, o grupo de licenciandos com menor percentual de concordância foram os evangélicos $(18,4 \%)$, seguidos pelos católicos (45,8\%), sem religião $(59,1 \%)$ e espiritualistas ${ }^{6}(61,1 \%)$. É interessante também analisar as justificativas empregadas para discordar da afirmação. Enquanto em espiritualistas e católicos a maior parte das discordâncias não lançava mão de argumentos religiosos (85,7\% e 93,8\%, respectivamente), entre os evangélicos tal relação se invertia, sendo encontradas justificativas com argumentos de natureza religiosa (75,7\%). Alguns exemplos: "Porque eu acredito no criacionismo, e não no evolucionismo", "Por exemplo, não consigo visualizar o homem vindo do macaco. Não consigo acreditar nessa história de atmosfera primitiva, coacervados, etc.", "Acredito que Deus criou o universo com todas as espécies que hoje existem".

A segunda afirmação declarava que o ser humano é a única espécie atual racional, perguntando aos licenciandos se existe ou não uma razão para esse fato. Para 50,0\% dos evangélicos há um motivo religioso para essa singularidade, enquanto a mesma resposta foi encontrada em apenas 15,8\% dos espiritualistas e 5,1\% dos católicos.

Diante da questão "a espécie humana surgiu a partir de outra espécie?”, uma vez mais emergiu a singularidade das posições dos evangélicos: apenas 38,5\% deles responderam afirmativamente, enquanto assim o fizeram $92,0 \%$ dos sem religião, 86,7\% dos espiritualistas e 85,0\% dos católicos. O mesmo cenário foi encontrado na afirmação seguinte, “Todos os seres vivos estão sujeitos à transformação ao longo do tempo, dando origem a novas espécies”. Concordaram com ela apenas $45,1 \%$ dos evangélicos, em comparação com 90,9\% dos sem religião, 88,3\% dos católicos e 84,2\% dos espiritualistas. Mais ainda, 35,3\% optaram pela alternativa "Não há comprovação de que os seres vivos se modificam dando origem a outros seres ao longo do tempo", opção escolhida por apenas 10,5\% dos espiritualistas, 4,5\% dos sem religião e 1,7\% dos católicos.

A imagem dos evangélicos como um grupo monolítico representa decerto um estereótipo diante da diversidade de modos de condutas e posturas encontrados no interior de uma mesma comunidade religiosa. No entanto, como procuramos enfatizar, em função de questões doutrinárias e de uma visão de mundo comum, alguns posicionamentos parecem ser mais frequentes nesse grupo, o que não significa que individualmente as mediações realizadas não variem de acordo com as experiências de cada um. Esse entendimento tornou possível a compreensão de que esses alunos e outros licenciandos, bem como professores,

Foram incluídas nessa espíritas kardecistas e os de religiões de matriz africana. os saberes científicos, o que também foi evidenciado por Sepulveda e El-Hani (2004) e Teixeira e Andrade (2014). 
Tal observação pode ajudar a concluir que seja possível a convivência simultânea tanto de concepções científicas como religiosas, cada qual sendo utilizada em seus contextos mais pertinentes (MORTIMER, 1996). Desse modo, o objetivo a ser alcançado pelo professor em sala de aula não seria o convencimento dos alunos em favor das explicações científicas. Nesse sentido, as salas de aula da escola e da universidade, cada uma com suas especificidades e preocupações distintas, assumem uma posição de destaque ao funcionarem como espaços não apenas de transmissão de conteúdos específicos de modo desarticulado e desprovidos de um significado maior, mas como locais em que esses alunos podem entrar em contato com diversos modos de pensar. Ensina-se, antes de mais nada, para que os alunos tenham acesso a outros conjuntos de saberes e sejam capazes de construir visões de mundo mais complexas que envolvam, em diferentes graus, oportunidades de incorporação de saberes provenientes de diferentes áreas. Dispondo de um repertório de explicações mais ampliado, tais alunos poderão fazer escolhas mais conscientes em diferentes situações de suas vidas. O acesso ao conhecimento enquanto um direito de todos deve também ser encarado como uma oportunidade de corrigir condições de acesso diferenciado à informação, uma das poucas oportunidades de acesso a um corpo de saberes diferente do que se encontra na família ou na comunidade de origem. Por fim, ensinam-se ciências e biologia para ajudar os alunos a adquirirem uma ferramenta crítica capaz de ser utilizada inclusive contra versões hegemônicas da própria atividade científica, tornando possível uma contestação a partir de sua própria lógica e de seus pressupostos.

Criar esse espaço para a recepção de novas ideias envolve escapar da saída técnica da pura transmissão do conteúdo formal - que não deve, contudo, deixar de ser valorizado - e também do desprezo por todos os saberes trazidos pelos alunos a partir de suas vivências, por mais absurdos que possam parecer sob a óptica da ciência. Esse processo envolve o reconhecimento de que a valoração dos diferentes saberes depende também da esfera em que são empregados, e não de um critério de validação único que coloque os saberes científicos acima de todos os outros nos mais diversos campos da existência humana. Essa postura dialógica em relação aos diferentes saberes, tão diferente daquela adotada pelos fundamentalistas religiosos em diferentes áreas, é aquela que pode apresentar maiores possibilidades, operando desse modo pelo estranhamento.

Segundo essa lógica, esse espaço dialógico, embora marcado pelo respeito mútuo e pela ausência de desqualificação das posições diferentes, deve promover constantemente um tensionamento que seja capaz de desarticular zonas de conforto, resgatando o potencial heurístico positivo do conflito, empregado de maneira não necessariamente excludente. Isso não significa deixar de reconhecer algumas situações em que as duas explicações podem mostrar-se irreconciliáveis, como a 
defesa da ideia de uma Terra com menos dez mil anos e o conjunto dos conhecimentos produzidos pela paleontologia, por exemplo.

Portanto, espera-se que, quando atuarem com suas turmas, os futuros professores possam reconhecer que mais importante do que o ensino de determinados conteúdos seja a forma como eles são trabalhados, destacando situações que destoem das visões tradicionais dos alunos. Desse modo, os conteúdos abordados deixam de ser objetivos importantes apenas em si mesmos e se tornam instrumentais nesse processo de aprendizado. Como destacado por Ferreira (2008), a base semântica em que se ancora o discurso neodarwinista é fundada em unidades lexicais como acaso, acidente e evolução, enquanto as do criacionismo se baseiam em unidades como projeto, propósito e criação. Muitos desses alunos apresentam uma visão do mundo natural marcada pela ideia de perfeição, ordem estática, harmonia, propósito e utilitarismo, na qual todos os seres vivos apresentam estruturas e organização que sempre exercem alguma função da maneira mais eficiente possível. Explorar os inúmeros exemplos de estruturas vestigiais, extinções em massa, construções corporais "possíveis" que operam dentro de suas limitações, formas de transição e mudanças de função de estruturas ao longo do processo evolução são abordagens que permitem trabalhar muitos dos conteúdos a partir da ótica do estranhamento.

Defende-se, assim, o pluralismo epistemológico em diferentes contextos, reconhecendo como educador o papel de delimitar as fronteiras entre as diferentes epistemologias ao mesmo tempo em que se criam as condições para que os alunos desenvolvam a habilidade de discriminar diferentes argumentos em disputa, de acordo com suas capacidades e limitações. As diversas situações, questionamentos e diálogos que podem ser produzidos nesse processo são, sem dúvida, potentes para que os futuros professores se preparem para lidar com as diferentes situações em que podem estar envolvidos nas salas de aula diante do avanço do criacionismo.

Diante das evidências trazidas à análise, torna-se ilusório pensar que alunos e professores com essas vinculações religiosas adotarão integralmente os conteúdos biológicos propostos curricularmente, abandonando por completo suas opiniões anteriores, mesmo que sejam apresentados de maneira coerente e inteligível. Essa é uma atitude que se revela, na maior parte dos casos, uma enorme mistificação. Segundo Cobern (1996), a visão racionalista aí embutida representa uma noção estreitamente concebida do papel que o conhecimento desempenha na vida de um indivíduo, e falha em perceber que as concepções cotidianas dos futuros professores de biologia e estudantes diferem das científicas pelo fato de servirem a diferentes propostas. Uma das respostas para lidar com esse impasse veio de uma abordagem que mereceu grande atenção nas últimas décadas, a qual passou a levar em conta a relação 
entre educação científica e o ambiente cultural do qual os alunos são oriundos. Essa ideia expandiu ainda mais a noção de construtivismo, que passou a incluir um componente cultural em sua estrutura, que Cobern (1994) denominou "construtivismo contextual”, o qual, segundo ele, seria uma abordagem construtivista cultural que concebe o aprendizado como algo que vai além de uma atividade unicamente individual, ocorrendo em um contexto social.

Os pontos de vista encontrados no construtivismo contextual de Cobern (1994) também se fazem presentes no modelo de perfis conceituais de Mortimer (1996). O autor afirma que os conhecimentos de um indivíduo sobre determinado conceito são estruturados a partir de influências provenientes de diferentes zonas epistemológicas e ontológicas estruturadas hierarquicamente e organizadas caracterizando um perfil que é construído a partir do conjunto de experiências vividas pelo indivíduo, no qual convivem múltiplas influências (MORTIMER, 1996). Somente levando em conta essas questões tais conceitos poderão adquirir maior relevância e sentido para os alunos.

Desse modo, o conceito de interculturalidade pode ser útil para entender algumas questões envolvidas no embate entre posicionamentos religiosos de alguns alunos e o papel da escola e dos professores, bem como na formação inicial, diante dessa situação. Uma de suas principais características é o rompimento com uma visão essencialista das culturas e identidades culturais, as quais são encaradas como em permanente processo de construção e interação com as influências de outros grupos culturais que fazem parte da sociedade, em um processo de construção de identidades abertas (CANDAU, 2009).

\section{CONSIDERAÇÕES FINAIS}

A partir da análise do histórico das matrizes evangélica conservadora e do criacionismo, procuramos centrar o debate, escapando de visões que o encaram como um embate entre ciência e religião. Essa análise permite evidenciar posições em sua maioria marcadas por visões de mundo que exibem em algum grau explicações simplistas e dogmáticas para os fenômenos à sua volta. Tais explicações, algumas vezes bastante elaboradas, têm como característica comum o fato de repousarem sobre um conjunto relativamente pequeno de certezas na explicação dos diferentes fenômenos biológicos, físicos e sociais, traduzindo-se em uma situação de estabilidade. Questões bastante complexas, passíveis de serem abordadas sob diferentes aspectos, encontram respostas simples e unívocas sobre temas como a origem da espécie humana, sexualidade, gênero e pluralismo religioso, e são equacionadas a partir de um repertório restrito de explicações. Nessa visão de mundo, quase todo tipo de mudança ou incerteza é encarada como sinônimo de imperfeição e 
instabilidade. Viver nesse mundo de certezas produz um forte sentido para sua compreensão de mundo e orientação pessoal em seu interior, sendo por isso muitas vezes uma perspectiva muito cara ao sujeito, defendida com muita intensidade.

Nesse sentido, qualquer outra forma de pensar que também opere tomando por base certezas absolutas seguramente disputará espaço em condição desvantajosa com a sua visão de mundo religiosa. Assim, apresentar os saberes oriundos da atividade científica como verdade absoluta sobre a natureza dos fenômenos que descrevem, além de incidir em graves incorreções epistemológicas, acaba muitas vezes por ser uma abordagem pouco eficaz. Acredita-se que uma abordagem mais promissora consista em apresentar a ciência como um campo de problematização e descobertas que sempre são parciais. É necessário fomentar tanto na formação de professores de biologia como nos alunos da educação básica a possibilidade de produzir uma sensação de estabilidade fundada não na produção de certezas, mas em uma dinâmica constante de substituição de explicações, permanentemente refeitas pela atividade humana. É preciso entender que as construções científicas nada têm de cumulativas, lineares ou progressivas, mas que se processam por avanços e recuos, disputas, perdas de informação e sua recuperação, além de um espaço generoso para o acaso, o circunstancial. No lugar apenas de um mundo ordenado, em que tudo encontra sempre uma explicação alentadora e existe apenas devido a alguma razão moral ou finalista, há algum espaço também para a magia de um mundo em permanente descoberta.

Assim sendo, pode ser útil o emprego de diversos exemplos da história e da filosofia da ciência ao abordar diferentes conceitos ou descobertas, permitindo entender os processos envolvidos na produção dos conhecimentos científicos bem como procurar demarcar os limites da atividade científica, permitindo que eles entendam que tipo de conhecimentos faz parte dessa maneira de produzir explicações para o mundo. Por mais que essa tentativa de demarcação possa por vezes se revelar complicada, como destacam autores como Laudan (1986), podendo por vezes ser muito difícil delimitar o que pode ou não ser caracterizado como ciência, certamente ela se revela extremamente eficaz para evidenciar casos que claramente não fazem parte da ciência, como é o caso do criacionismo.

Por fim, diante do que foi exposto, é necessário fazer uma distinção entre a presença de discussões sobre temas religiosos nas aulas de ciências e biologia, como parte das dúvidas e questionamentos trazidos pelos alunos, e a presença do criacionismo como currículo prescrito em livros didáticos e como conteúdo científico nessas aulas. Na verdade estes últimos utilizam os primeiros como um pretexto para estender a sua estratégia de ação política para o campo escolar. Enquanto 
os diferentes conflitos de nossos alunos devem ser entendidos como componentes naturais das ideias que eles podem trazer para a sala de aula, devendo ser discutidos à medida que se manifestem durante o curso como parte inerente do processo de aprendizado, acreditamos que o movimento criacionista deve ser combatido como ingerência indevida em campos alheios ao seu contexto de produção original. As dúvidas e posicionamentos dos alunos são parte integrante do processo de realização de mediações com os conteúdos que se deseja transmitir, algo bem diferente do que pretende a agenda política do criacionismo, que deve ser fortemente rejeitada na escola.

\section{REFERÊNCIAS}

APPLE, Michael. Evolution versus Creationism in Education. Educational Policy, n. 22, p. 327-335, 2008.

ARMSTRONG, Karen. Em nome de Deus: o fundamentalismo no judaísmo, no cristianismo e no islamismo. São Paulo: Companhia das Letras, 2001.

ASSOCIAÇÃO BRASILEIRA DE ENSINO DE BIOLOGIA. Carta aberta. Rio de Janeiro: SBEnBio, Abrapec, 24 nov. 2014. Disponível em: <http://www.sbenbio.org.br/wordpress/wp-content/ uploads/2014/11/Carta-Aberta-SBEnBio-ABRAPEC.pdf>. Acesso em: 14 abr. 2016.

BRANCH, Glenn; SCOTT, Eugenie. Manobras mais recentes do criacionismo. Scientific American Brasil, n. 81, p. 82-89, 2009.

CANDAU, Vera Maria. Direitos humanos, educação e interculturalidade: as tensões entre igualdade e diferença. In: CANDAU, Vera Maria (Org.). Educação intercultural na América Latina: entre concepções, tensões e propostas. Rio de Janeiro: 7 Letras, 2009. p. 154-173.

COBERN, William. Comments and Criticism. Point: belief, understanding, and the teaching of evolution. Journal of Research in Science Teaching, n. 31, p. 583-590, 1994.

COBERN, William. Worldview theory and conceptual change in science education. Science Education, n. 80, p. 579-610, 1996.

CUNHA, Luiz Antônio. Autonomização do campo educacional: efeitos do e no campo religioso. Revista Contemporânea de Educação, v. 1, n. 2, p. 1-15, 2006. Disponível em: <https://revistas.ufrj. br/index.php/rce/article/view/1501>. Acesso em: 15 abr. 2016.

CUNHA, Magali do N. A Explosão Gospel. Um olhar das Ciências Humanas sobre o cenário evangélico no Brasil. Rio de Janeiro: Mauad X, 2007. 231p.

DORVILLÉ, Luís Fernando M. Religião, escola e ciência: conflitos e tensões nas visões de mundo de alunos de uma licenciatura em ciências biológicas. 2010. Tese (Doutorado) - Faculdade de Educação, Universidade Federal Fluminense, Niterói, 2010.

FERREIRA, Nilson Cândido. Evolucionismo e criacionismo: aspectos de uma polêmica. 2008. Tese (Doutorado) - Instituto de Estudos da Linguagem, Universidade Estadual de Campinas, Campinas, 2008.

FONSECA, Lana Cláudia de Souza. Quem somos? De onde viemos? Para onde vamos? Religião e ciência encontram-se nas aulas de ciências na escola pública. Ciência em Tela, n. 1, p. 1-11, 2008.

GOULD, Stephen Jay. Pilares do tempo: ciência e religião na plenitude da vida. Rio de Janeiro: Rocco, 2002.

LARSON, Edward. Trial and error: the American controversy over creation and evolution. New York: Oxford University Press, 2003.

LAUDAN, Larry. Some problems facing intuitionist meta-methodologies. Synthese, n. 67, v. 1, p. 115-129, 1986. 
LICATTI, Fábio. O ensino de evolução biológica no nível médio: investigando concepções de professores de biologia. 2005. Dissertação (Mestrado) - Universidade Estadual Paulista, Bauru, 2005.

MARANDINO, Martha; SELLES, Sandra E.; FERREIRA, Marcia S. Ensino de biologia: histórias e práticas em diferentes espaços educativos. São Paulo: Cortez, 2011.

MARTINS, Maurício Vieira. De Darwin, de caixas-pretas e do surpreendente retorno do “criacionismo”. História, ciências, Saúde, n. 8, p. 739-756, 2001.

MATZKE, Nicholas. The evolution of creationist movements. Evolution: education and outreach, n. 3, v. 2, p. 145-162, 2010.

MAYR, Ernst. O desenvolvimento do pensamento biológico. Brasília: Editora UnB, 1998.

MAYR, Ernst. Uma ampla discussão: Charles Darwin e a gênese do moderno pensamento evolucionário. Ribeirão Preto: Funpec, 2006.

MENDONÇA, Antônio Gouvêa. Evolução histórica e configuração atual do protestantismo no Brasil In: MENDONÇA, A. G.; VELASQUES FILHO, P. Introdução ao Protestantismo no Brasil. São Paulo: Loyola, 2002. p. 11-59.

MOORE, Randy. Creationism in the United States: the aftermath of the scopes trial. The American Biology Teacher, n. 60, p. 568-577, 1998.

MOORE, Randy. The revival of creationism in the United States. Journal of Biological Education, n. 35 , p. $17-21,2000$.

MOORE, Randy. The lingering impact of the scopes trial on high school Biology textbooks. Bioscience, n. 51, p. 790-796, 2001.

MORTIMER, Eduardo Fleury. Construtivismo, mudança conceitual e ensino de ciências: para onde vamos? Investigações em Ensino de ciências, n. 1, p. 20-39, 1996.

NOVAES, Regina Reyes. Pentecôtisme à la brésilienne: des controverse en cours. Archive de sciences sociales des religions, n. 105, p. 125-143, 1999.

NUMBERS, Ronald. Darwinism comes to America. Massachusetts: Harvard University Press, 1998.

NUMBERS, Ronald. The creationists: from scientific creationism to intelligent design.

Massachusetts: Harvard University Press, 2006.

PARKER, Franklin. Why the evolution/creation battle rages: what educators can do. Morgantown: West Viriginia University, out. 1981. Disponível em: <http://files.eric.ed.gov/fulltext/ED207904. pdf $>$. Acesso em: 15 abr. 2016.

RAZERA, Júlio César Castilho; NARDI, Roberto. Ética no ensino de ciências: atitudes e desenvolvimento moral nas controvérsias. In: RAZERA, Júlio César Castilho; NARDI, Roberto (Org.). Educação em ciências: da pesquisa à prática docente. São Paulo: Escrituras, 2001. p. 41-56.

RUSE, Michael. The evolution-creation struggle. Massachusetts: Harvard University Press, 2006.

RUTHVEN, Malise. Fundamentalism: a very short introduction. Oxford: Oxford University Press, 2007.

SCHÜNNEMAN, Haller Elinar Stach. O papel do "criacionismo científico" no fundamentalismo protestante. Estudos de Religião, n. 35, p. 64-86, 2008.

SCOTT, Eugenie C. Antievolution and Creationism in the United States. Annual Review of Anthropology, n. 26, p. 263-289, 1997.

SCOTT, Eugenie C. Evolution versus creationism: an introduction. Los Angeles: University of California Press, 2004.

SCOTT, Eugenie C. Creationism and evolution: it's the American Way. Cell, n. 124, p. 449-451, 2006.

SCOTT, Eugenie C. Cans and Can'ts of teaching evolution. Oakland: National Center for Science Education, 17 out. 2008. Disponível em: <http://ncse.com/evolution/education/cans-cantsteaching-evolution>. Acesso em: 15 abr. 2016.

SCOTT, Eugenie C.; MATZKE, Nicholas. Biological design in science classrooms. Proceedings of the National Academy of Sciences of the United States of America, n. 104, Suppl. 1, p. 8669-8676, 2007. 
SEPULVEDA, Cláudia de Alencar Serra; EL-HANI, Charbel Niño. Ensino de evolução: uma experiência na formação inicial de professores de biologia. In: TEIXEIRA, P. M. M.; RAZERA, J. C. C. (Org.). Ensino de ciências: pesquisas e pontos em discussão. Campinas: Komedi, 2009. p. 21-45.

SEPULVEDA, Cláudia de Alencar Serra; EL-HANI, Charbel Niño. Quando visões de mundo se encontram: religião e ciência na trajetória de formação de alunos protestantes de uma Licenciatura em Ciências Biológicas. Investigações em Ensino de Ciências, n. 9, p. 137-175, 2004.

SOUZA, Sandro de. A goleada de Darwin: sobre o debate criacionismo/darwinismo. Rio de Janeiro: Record, 2009.

TEIXEIRA, Pedro. Ensino de evolução e religiosidade dos estudantes: reflexões sobre a prática pedagógica. Revista da Associação Brasileira de Ensino de Biologia, n. 7, p. 6161-6172, 2014.

TEIXEIRA, Pedro; ANDRADE, Marcelo. Entre as crenças pessoais e a formação acadêmica: como professores de biologia que professam fé religiosa ensinam evolução? Ciência \& Educação, n. 20, p. 297-313, 2014.

TIDON, Rosana; LEWONTIN, Richard C. Teaching evolutionary biology. Genetics and Molecular Biology, n. 27, p. 124-131, 2004.

VEIGA, Edison; BRANDÃO, Raquel. Teoria da evolução não é incompatível com fé, diz papa. O Estado de S. Paulo, São Paulo, 28 out. 2014.

WILLIAMS, Robert. Scientific creationism: an exegesis for a religious doctrine. American Anthropologist, New Series, n. 85, p. 92-102, 1983.

\section{LUÍS FERNANDO MARQUES DORVILLÉ}

Professor Adjunto do Departamento de Ciências da Faculdade de Formação de Professores - FFP - da Universidade do Estado do Rio de Janeiro - UERJ -, Rio de Janeiro, Rio de Janeiro, Brasil

ldorville@gmail.com

\section{SANDRA LÚCIA ESCOVEDO SELLES}

Professora Titular do Departamento de Sociedade, Educação e Conhecimento da Faculdade de Educação da Universidade Federal Fluminense - UFF -, Niterói, Rio de Janeiro, Brasil

escovedoselles@gmail.com 